NÉCROLOGIE

\title{
ALEXANDRE HAY N'EST PLUS
}

M. Alexandre Hay, ancien président du CICR, s'est éteint le 23 août 1991 à Genève à l'âge de 72 ans. Avec lui le Mouvement international de la Croix-Rouge et du Croissant-Rouge perd un grand serviteur dont l'action a été marquée par son total engagement en faveur du respect du droit, de la promotion des idéaux humanitaires et de la paix par le dialogue et la concertation.

Né en 1919, Alexandre Hay effectua ses études à Genève, il obtint sa licence en droit en 1941 et son brevet d'avocat en 1944. Il est entré au Département politique fédéral à Berne en 1945 et y restera jusqu'en 1948; il est ensuite Secrétaire à la Légation de Suisse à Paris de 1948 à 1953. En 1954, il devient directeur de division chargé des affaires internationales à la Banque Nationale Suisse à Zurich. De 1955 à 1966, il est directeur et suppléant du chef du $\mathrm{II}^{\mathrm{e}}$ Département à la Banque Nationale Suisse à Berne dont il deviendra en 1966 et jusqu'en 1976 directeur général et chef du $\mathrm{II}^{\mathrm{e}}$ Département puis viceprésident de la Direction générale.

Alexandre Hay fut nommé en 1975 membre du Comité international de la Croix-Rouge, dont il assura la présidence de 1976 à 1987. Depuis cette date, il poursuivit son action humanitaire en qualité de président de la Commission sur la Croix-Rouge, le Croissant-Rouge et la paix et fut l'artisan inspiré de la Campagne mondiale pour la protection des victimes de la guerre.

Le développement spectaculaire qu'a connu le CICR au cours de ses dix années de mandat, jalonnées par de nombreux drames*, a mis en évidence le sens profond de l'humain du président Hay, son esprit de service, sa bonté rayonnante, ses qualités d'animateur. Doté d'un

* Cf. «Sous la présidence de M. Alexandre Hay, le CICR de 1976 à 1987 - La croissance maîtrisée», Revue internationale de la Croix-Rouge, No 768 , novembre-décembre 1987, pp. 648-667. 
rare bon sens, agissant avec une sincérité qui forçait les convictions, Alexandre Hay n'a jamais cédé sur les principes et a mené avec discernement et courage un combat incessant pour plus d'humanité.

Un service commémoratif a eu lieu le 30 août à la Cathédrale Saint-Pierre de Genève au cours duquel une assistance nombreuse, comprenant les membres de l'Assemblée et du Conseil exécutif du CICR et beaucoup de ses collaborateurs, des représentants de Sociétés nationales de la Croix-Rouge et du Croissant-Rouge et de leur fédération, la Ligue, ainsi que des représentants des autorités fédérales et cantonales s'est unie dans un même recueillement, s'associant avec émotion à l'hommage que son successeur, $M$. Cornelio Sommaruga, a rendu au président défunt, et dont la Revue tient à faire partager ses lecteurs.

\section{La Revue}

\section{Hommage à Alexandre Hay}

Depuis quelques mois Alexandre Hay faisait face avec un tranquille courage et avec lucidité aux assauts répétés d'un mal dont il soupçonnait la gravité. Sa confiance dans ses médecins n'a jamais failli, mais, homme d'une foi profonde, il savait que si le devoir de l'homme consiste à tout mettre en ruvre pour assurer le succès de ses entreprises, le dernier mot restait au Maître de la vie. Il n'a jamais fait étalage de ses convictions religieuses, mais à l'heure de sa dernière grande décision, il n'a éprouvé aucune gêne à affirmer, en toute simplicité, sa soumission sans réserve à la volonté de Dieu.

Jusqu'au 23 août, avec lui-même et les siens, nous partagions sa confiance et nous espérions. Hélas, les choses n'ont pas évolué dans le sens de nos voux et la réalité qui s'est imposée à nous coupait court à toutes nos espérances. Profondément émus, nous les membres et collaborateurs du CICR, tous les amis de la Croix-Rouge et du Croissant-Rouge, nous avons partagé la douleur de sa famille et de ses proches, plus particulièrement celle de $M^{\text {me }}$ Hay qui, depuis les premières atteintes de la maladie, l'a entouré de son inlassable sollicitude. 